\title{
Estudo in vitro da microinfiltração marginal em cavidades submetidas ao tratamento com laser de Er:YAG e restauradas com materiais estéticos
}

\section{In vitro study of the microleakage in cavities submitted to treatment with Er:YAG laser and restored with aesthetic materials}

\author{
Margareth ODA* \\ Paulo ZÁRATE-PEREIRA** \\ Edmir MATSON***
}

\begin{abstract}
ODA, M.; ZÁRATE-PEREIRA, P.; MATSON, E. Estudo in vitro da microinfiltração marginal em cavidades submetidas ao tratamento com laser de Er:YAG e restauradas com materiais estéticos. Pesqui Odontol Bras, v. 15, n. 4 , p. 290-295, out./dez. 2001.

O objetivo desse estudo foi avaliar, in vitro, a microinfiltração marginal em cavidades de classe V submetidas ao tratamento com laser de Er:YAG e restauradas com materiais estéticos. Foram selecionados 60 dentes humanos e realizados preparos de classe V no terço cervical das faces vestibular e lingual. A técnica restauradora seguiu as especificações dos fabricantes. Os dentes foram divididos em três grupos de 20 dentes: Grupo 1 (controle), Grupo 2: procedeu-se previamente à restauração um tratamento com laser de Er:YAG na superfície do esmalte do ângulo cavo-superficial, Grupo 3: antes da restauração, aplicou-se uma fina camada de cimento de $\mathrm{Ca}(\mathrm{OH})_{2}$ na parede axial. Cada grupo foi dividido em quatro subgrupos e restaurados com materiais estéticos diferentes. Todos os dentes foram submetidos a ciclagem térmica e técnica de infiltração com nitrato de prata a 50\%. Com base nos resultados, concluiu-se que existem diferenças entre as doze condições experimentais realizadas. As amostras que apresentaram maior microinfiltração foram, em primeiro lugar, as com tratamento com laser de Er:YAG e restauradas com cimento de ionômero de vidro fotoativado. Em segundo, as tratadas com laser de Er:YAG e restauradas com a técnica do sanduíche (cimento de ionômero de vidro convencional + resina composta fotoativada). Em terceiro, as restauradas com cimento de ionômero de vidro fotoativado, e por último as restauradas com a técnica do sanduíche.
\end{abstract}

UNITERMOS: Infiltração dentária; Materiais dentários; Lasers.

\section{INTRODUÇÃO}

A microinfiltração é um dos principais inconvenientes dos materiais estéticos, devido à diferença de coeficiente de expansão térmica entre a estrutura dental e o material restaurador e à falta de um sistema adesivo dentinário que seja considerado ideal. Isso se deve à própria constituição da dentina que é composta de $50 \%$ de porção mineral, $30 \%$ de matéria orgânica e $20 \%$ de fluido dentinário ${ }^{19}$ e aos componentes dos sistemas adesivos. O condicionamento ácido, desde sua instituição por BUONO$\mathrm{CORE}^{8}$ em 1955, é o tratamento de eleição quando se trata de tentar um melhor vedamento da estru- tura dentária com sistemas de adesão ${ }^{27}$. No entanto, a ação que o ácido promove na dentina, cria uma permeabilidade, ou seja, um potencial irritativo à polpa $^{26}$ e uma conseqüente infiltração bacteriana, são as causas do comprometimento no selamento das restaurações.

Atualmente, muitas tentativas têm sido criadas para melhorar o vedamento das restaurações estéticas. Assim, têm surgido novos materiais como os compômeros $^{6,21}$, materiais restauradores com sistema adesivo de última geração; técnicas mistas de restaurações com cimento de ionômero de vi $\mathrm{dro}^{24}$, até diferentes tratamentos na superficie den-

\footnotetext{
*Professora Doutora; ***Professor Titular - Departamento de Dentística, Faculdade de Odontologia da USP.

** Professor da Disciplina de Cariologia da Universidade Federal do Mato Grosso do Sul, Mestre e Doutorando pela Faculdade de Odontologia da USP.
} 
ODA, M.; ZÁRATE-PEREIRA, P.; MATSON, E. Estudo in vitro da microinfiltração marginal em cavidades submetidas ao tratamento com laser de Er:YAG e restauradas com materiais estéticos. Pesqui Odontol Bras, v. 15, n. 4, p. 290-295, out./dez. 2001.

tária, inclusive a realização ou não de bisel no ângulo cavo-superficial dos preparos ${ }^{16,22}$.

Entre os mais recentes tratamentos de superficie, encontra-se a irradiação com laser de Er:YAG em tecidos duros que vem sendo muito pesquisa$\mathrm{do}^{11}$. O laser de Er:YAG tem uma série de propostas para o seu uso, uma delas é o condicionamento do esmalte e dentina ${ }^{25}$. Comparando a superficie do esmalte e da dentina após a aplicação de laser de Er:YAG, GROSS et al. ${ }^{15}$ (1992) observaram, no esmalte, detritos e áreas onde houve desintegração de prismas, removendo os fragmentos superficiais, resultando em um aspecto rugoso. Portanto, o laser promoveu ataque adicional criando um padrão microrretentivo. Em 1992, LI et al. ${ }^{18}$ observaram superficies irregulares sugerindo retenções micromecânicas benéficas para a realização do procedimento adesivo. Quanto ao selamento de cavidades, WRIGHT et $a l^{30}$, em 1992, compararam a microinfiltração em cavidades preparadas convencionalmente, atacadas por ácido, e cavidades atacadas por laser, onde os autores concluíram que a microinfiltração foi similar, independente da técnica utilizada. KUMAZAKI ${ }^{17}$, em 1994, ao realizar semelhante estudo, porém em esmalte de dentes de bovinos, verificou que, dentro das condições efetuadas e com a energia de $600 \mathrm{~mJ}$ (densidade de energia $=8,5 \mathrm{~J} / \mathrm{cm}^{2}$ ), o ataque ao esmalte foi efetivo, sendo esse igual ou melhor que o do ataque ácido.

As técnicas de restaurações com cimento de ionômero de vidro (CIV) e compômeros são formas alternativas de restaurações estéticas, muito embora não apresentem bons resultados clínicos em relação a microinfiltração, como salientaram BRACKETT et al. ${ }^{6}$, em 1998. As restaurações comcompômeros, comparadas com as de resinas compostas e sistemas adesivos atuais, tiveram pior comportamento em relação ao vedamento, quando testadas por CHERSONI et al. ${ }^{9}$ (1997).

Muitas tentativas de melhorar a adesão e conseqüente diminuição da microinfiltração vem sendo realizadas com os mais diversos métodos ${ }^{1}$ nestes últimos anos, o que tem colaborado sobremaneira para o aperfeiçoamento dos materiais restauradores, porém, sem o sucesso esperado. Para isso, mais estudos são necessários a fim de se conseguir melhores resultados. O objetivo deste trabalho é avaliar o tratamento do ângulo cavo-superficial com laser de Er:YAG em cavidades de classe $\mathrm{V}$, na diminuição da microinfiltração.

\section{MATERIAL E MÉTODO}

Foram utilizados 60 pré-molares humanos, com superficies vestibular e lingual hígidas, armazenados em soro fisiológico. Cavidades de classe $\mathrm{V}$ foram preparadas nas faces vestibular e lingual de todos os dentes selecionados ${ }^{4}$. As dimensões das cavidades foram de, aproximadamente, 2,0 x 4,0 x 2,0 $\mathrm{mm}$, aferidos com paquímetro. Os preparos foram realizados com ponta diamantada 1091 (KG Sorensen) em ultra-alta velocidade e sob refrigeração com água e ar. O refinamento cavitário foi feito com instrumentos cortantes manuais: enxada $26 \mathrm{e}$ 26S e machado 14-15 (Duflex Inox Indústria e Comércio). Em seguida, fez-se a limpeza da cavidade com detergente aniônico (Tergentol). Depois, secou-se com leves jatos intermitentes de ar. As amostras foram divididas em três grupos de 20 dentes cada e esses, em 4 subgrupos. As cavidades foram restauradas com os seguintes materiais: resina composta fotoativada (Z100/adesivo Single Bond - 3M); Degufill Mineral/adesivo Etch \& Prime 3.0 - Degussa); cimento de ionômero de vidro fotoativado (Vitremer - 3M); cimento de ionômero de vidro convencional (Ketac Bond - ESPE); compômero (F2000 - 3M) e cimento de hidróxido de cálcio (Dycal - Dentsply).

O Grupo 1 (controle) totalizou 20 dentes, onde os preparos cavitários foram restaurados segundo técnica sugerida pelo fabricante de cada material restaurador, desde o preparo da superficie até o polimento final.

Dessa forma, obtiveram-se 4 subgrupos (5 dentes) do Grupo 1:

- Subgrupo 1.1: dentes restaurados com resina composta Z100 + adesivo Single Bond (3M).

- Subgrupo 1.2: dentes restaurados com cimento de ionômero de vidro Vitremer MR (3M).

- Subgrupo 1.3: dentes restaurados com a técnica do sanduíche, com cimento de ionômero de vidro convencional Ketac-Bond (ESPE) + resina composta Degufill Mineral (Degussa).

- Subgrupo 1.4: dentes restaurados com compômero F2000 (3M).

O Grupo 2 totalizou 20 dentes, onde os preparos cavitários foram restaurados, com prévia aplicação do laser de Er:YAG, na superfície do esmalte circundante. O laser utilizado foi o Kavo Key Laser do LELO, da Faculdade de Odontologia da USP. O Er:YAG consiste num laser em estado sólido, cujo meio ativo é um cristal de YAG ("Yttrium", "Aluminum", "Garnet" - ítrio, alumínio, granada). O aparelho emite num comprimento de onda de $2,94 \mu \mathrm{m}$ sendo, portanto, uma irradiação infravermelha, da 
ODA, M.; ZÁRATE-PEREIRA, P.; MATSON, E. Estudo in vitro da microinfiltração marginal em cavidades submetidas ao tratamento com laser de Er:YAG e restauradas com materiais estéticos. Pesqui Odontol Bras, v. 15, n. 4, p. 290-295, out./dez. 2001.

porção invisível do espectro que necessita de uma luz guia para sua focalização. O laser foi utilizado de forma desfocada, a uma distância de $20 \mathrm{~mm}$ do esmalte circundante do ângulo cavo-superficial, e com uma saída de água com velocidade de $24 \mathrm{ml} / \mathrm{min}$. Os dentes foram irradiados a uma energia de $80 \mathrm{~mJ}$ e freqüência de $2 \mathrm{~Hz}^{27}$. Dessa forma, obtiveram-se 4 subgrupos do Grupo 2, seguindo a mesma ordem de material restaurador do Grupo 1, formando, portanto, os subgrupos 2.1; $2.2 ; 2.3$ e 2.4 .

O Grupo 3 totalizou 20 dentes, onde os preparos cavitários receberam uma película fina de cimento de hidróxido de cálcio na parede axial, para proteção do complexo dentino-pulpar. Dessa forma, obtiveram-se 4 subgrupos do Grupo 3 seguindo a mesma ordem de material restaurador do Grupo 1, formando, portanto, os subgrupos 3.1; $3.2 ; 3.3$ e 3.4 .

Após o polimento das restaurações, os dentes foram armazenados em soro físiológico 0,9\% e mantidos em estufa a $37^{\circ} \mathrm{C}$ por 24 horas. A seguir, os dentes foram secos e impermeabilizados com camadas de esmalte cosmético em toda a estrutura dental, com exceção da região restaurada e áreas circunvizinhas. A tonalidade do esmalte foi diferente para cada subgrupo a fim de facilitar a identificação. Em seguida, foram submetidos à ciclagem térmica, que propicia avaliar os efeitos das diferenças entre os coeficientes de expansão térmica, do material restaurador e da estrutura dental, comprovando assim, as ações da variação da temperatura sobre os materiais restaurado$\operatorname{res}^{2,3,5,7}$. A ciclagem térmica foi realizada com 700 ciclos completos, em banhos alternados de temperaturas de 5 e $55^{\circ} \mathrm{C}$, permanecendo por um minuto em cada banho ${ }^{14}$, muito embora haja na literatura uma variedade de sugestões para números e temperatura de ciclos térmicos ${ }^{13}$. $\mathrm{Na}$ fase seguinte, os dentes foram imersos em solução de nitrato de prata a $50 \%$ (IPEN), durante um período de oito horas, em completa ausência de luz ${ }^{20}$. Essa metodologia permite, por detecção visual, perceber a existência de espaços entre o dente e o material restaurador ${ }^{10,12,16,20,23,28,29,31,32}$.

Passadas as 8 horas de imersão, as amostras foram retiradas da solução, lavadas em água corrente durante um minuto e secos com auxílio de papel absorvente. Com a finalidade de melhorar a manipulação, os corpos-de-prova foram embutidos em cubos de resina acrílica, transparente, para se obter melhor posicionamento na máquina de corte. Em seguida, foram seccionados no sentido vestíbulo-lingual, através da máquina de sec- cionamento (Labcut 1010, Extec - EUA), dividindo assim a restauração em duas porções, uma mesial e outra distal. Cada porção foi colocada sobre uma superficie plana com o lado de corte voltado para cima e expostos a uma lâmpada "photoflood" (GE do Brasil S.A.) de 250 watts, por cinco minutos ${ }^{16,28}$. A finalidade desse passo é revelar o nitrato de prata que, ao ser exposto à luz, adquire coloração escura. No tempo aproximado de cinco minutos, onde houver espaço na interface dente-restauração, é possivel verificar a presença dessa pigmentação.

A avaliação dos cortes foi realizada através de uma lupa estereoscópica (Olympus) com aumento de $50 \mathrm{X}$, e fotografados com filme Kodacolor ASA 100. As fotografias, em dimensões de $10 \mathrm{x}$ $15 \mathrm{~cm}$, foram avaliadas por três examinadores, que registraram o nivel de infiltração de acordo com a seguinte escala fornecida por RETIEF et al. ${ }^{23}$ em 1991:

- 0 - sem microinfiltração;

- 1 - microinfiltração até a junção amelo-dentinária;

- 2 - microinfiltração atingindo as paredes laterais do preparo;

- 3 - microinfiltração atingindo a parede axial do preparo.

\section{RESULTADO}

O planejamento estatístico foi executado no sentido de encontrar uma prova para decidir se diferentes amostras independentes eram provenientes de populações diferentes. Os valores amostrais quase que invariavelmente diferiram entre si, e o problema foi decidir se essas diferenças efetivas entre as amostras significavam diferenças efetivas entre as populações ou se representavam apenas variações casuais, que pudessem ser esperadas entre amostras aleatórias de uma mesma população. A técnica não-paramétrica de Kruskal-Wallis comprovou a hipótese de nulidade, ou de populações idênticas às médias (Tabela 1).

No caso presente, a hipótese de nulidade é de que não há diferença entre as 12 condições experimentais realizadas. Em contrapartida, a hipótese alternativa é de que existe diferença entre elas. Assim, aplicamos o teste de Kruskal-Wallis ao nível de 0,05 de probabilidade.

$O$ teste estatístico não-paramétrico de Kruskal-Wallis foi aplicado às médias dos postos e verificou-se que há diferenças entre as doze condições experimentais ao nivel de $1 \%$. Para conhecer quais as amostras diferentes entre si, realizou-se a com- 
ODA, M.; ZÁRATE-PEREIRA, P.; MATSON, E. Estudo in vitro da microinfiltração marginal em cavidades submetidas ao tratamento com laser de Er:YAG e restauradas com materiais estéticos. Pesqui Odontol Bras, v. 15, n. 4, p. 290-295, out./dez. 2001.

TABELA 1 - Resultado do teste de Kruskal-Wallis, para a média dos postos das doze condições experimentais realizadas ao nivel de 0,05 de probabilidade.

\begin{tabular}{l|c}
\hline \hline \multicolumn{2}{c}{ Teste de Kruskal-Wallis } \\
\hline Valor $(\mathrm{H})$ de Kruskal-Wallis calculado & 31,6487 \\
\hline Valor do X ${ }^{2}$ para 11 graus de liberdade & 31,65 \\
\hline Probabilidade de Ho para esse valor & $0,09 \%$ \\
\hline \multicolumn{2}{c}{ Significante ao nível de 1\% (Valores críticos $=0,01)$} \\
\hline \hline
\end{tabular}

Valor de $\mathrm{H}(11, \mathrm{n}=120)$ de Kruskal-Wallis calculado $=31,65(p=0,001)$. Conclusão: significante ao nível de probabilidade de $5 \%$.

paração entre as médias dos postos das amostras, com nivel de confiança de $5 \%$, onde foi possivel verificar que determinadas condições experimentais não mostraram diferença significante entre os valores. As situações que apresentaram diferenças estatisticamente significantes são apresentadas no Quadro 1.

\section{DISCUSSÃO}

A microinfiltração dos materiais restauradores tem sido bastante abordada na literatura ${ }^{10,12,16,21,23,28 \text {, }}$ 29,31,32 e com as mais diversas metodologias ${ }^{1}$. Todas através de detecção visual, que prova a existência da falta de vedamento que ocorre na interface dente/restauração. Atualmente, têm-se utilizado variações nas técnicas das restaurações, tentando-se com isso minimizar a microinfiltração, como é o caso do emprego da irradiação com laser de Er:YAG na superficie do esmalte cavo-superficial dos preparos cavitários.

A aplicação do laser de Er:YAG foi utilizada por GROSS et al. ${ }^{15}$ (1992) e LI et al. ${ }^{18}$ (1992). Nos estudos, os autores verificaram que o laser promoveu um ataque adicional ao esmalte, resultando num padrão microrretentivo, podendo ser sua efetividade, igual, ou melhor, que a do ataque ácido ${ }^{17}$. Entretanto, estas conclusões diferem-se das encontradas no presente estudo, pois se verificou que os padrões que mais favoreceram a microinfiltração foram quando da utilização do tratamento com laser de Er:YAG com o material restaurador cimento de ionômero de vidro fotoativado e do tratamento com laser de Er:YAG com a técnica do sanduíche (cimento de ionômero de vidro convencional + resina composta fotoativada).

As propostas de melhorar o comportamento clínico, principalmente no que se refere ao vedamen-
QUADRO 1 - Materiais utilizados nos três grupos experimentais.

\begin{tabular}{|c|c|}
\hline \multirow{4}{*}{$\begin{array}{c}\text { Grupo } 1 \\
\text { Técnica } \\
\text { convenional }\end{array}$} & RC Z100 + Adesivo Single Bond (3M) \\
\hline & CIV Vitremer MR (3M) \\
\hline & $\begin{array}{l}\text { Técnica do sanduíche: CIV Ketac Bond } \\
\text { (ESPE) + RC Degufill Mineral (Degussa) }\end{array}$ \\
\hline & Compômero F2000 (3M) \\
\hline \multirow{4}{*}{$\begin{array}{c}\text { Grupo } 2 \\
\text { Laser Er:YAG }\end{array}$} & RC Z100 + Adesivo Single Bond (3M) \\
\hline & CIV Vitremer MR (3M) \\
\hline & $\begin{array}{l}\text { Técnica do sanduíche: CIV Ketac Bond } \\
\text { (ESPE) + RC Degufill Mineral (Degussa) }\end{array}$ \\
\hline & Compômero F2000 (3M) \\
\hline \multirow{4}{*}{$\begin{array}{l}\text { Grupo } 3 \\
\mathrm{Ca}(\mathrm{OH})_{2}\end{array}$} & RC Z100 + Adesivo Single Bond (3M) \\
\hline & CIV Vitremer MR (3M) \\
\hline & $\begin{array}{l}\text { Técnica do sanduíche: CIV Ketac Bond } \\
\text { (ESPE) + RC Degufill Mineral (Degussa) }\end{array}$ \\
\hline & Compômero F2000 (3M) \\
\hline
\end{tabular}

$\mathrm{RC}=$ resina composta $; \mathrm{CIV}=$ cimento de ionômero $\mathrm{de}$ vidro.

to marginal, têm levado a indústria a lançar no mercado, uma grande variedade de materiais esté$\operatorname{ticos}^{6,21}$. O condicionamento ácido, instituído por BUONOCORE $^{8}$ em 1955, utilizado em larga escala na clínica atualmente e também eleito para a realização deste experimento, é o que tem apresentado melhores resultados no selamento marginal ${ }^{26,27}$, muito embora, como salientaram MARSHALL Jr. et al. $^{19}$ (1997) e SANTOS; BARBOSA ${ }^{26}$ (1998), os componentes da dentina e os constituintes dos sistemas adesivos, ainda não chegaram a um ideal quanto a diminuir a zero a infiltração marginal.

\section{CONCLUSÕES}

1. As análises permitiram verificar que existem diferenças entre as doze condições experimentais realizadas.

2. As amostras que apresentaram maior microinfiltração foram as tratadas com laser de Er:YAG + cimento de ionômero de vidro fotoativado, seguidas pelas tratadas com laser de Er:YAG e restauradas com a técnica do sanduíche (cimento de ionômero de vidro convencional + resina composta fotoativada), as restauradas com cimento de ionômero de vidro fotoativado e as restauradas com a técnica do sanduíche. 
ODA, M.; ZÁRATE-PEREIRA, P.; MATSON, E. Estudo in vitro da microinfiltração marginal em cavidades submetidas ao tratamento com laser de Er:YAG e restauradas com materiais estéticos. Pesqui Odontol Bras, v. 15, n. 4, p. 290-295, out./dez. 2001.

ODA, M.; ZÁRATE-PEREIRA, P.; MATSON, E. In vitro study of the microleakage in cavities submitted to treatment with Er:YAG laser and restored with aesthetic materials. Pesqui Odontol Bras, v. 15, n. 4, p. 290-295, out./dez. 2001.

The aim of this in vitro study was to evaluate marginal microleakage in class $\mathrm{V}$ preparations submitted to treatment with Er:YAG laser and restored with aesthetic materials. Sixty human molars were selected and class V cavities were prepared on the buccal and lingual aspects of their cervical thirds. The restorative technique followed the instructions of the manufacturers. The samples were divided in 3 groups of 20 teeth each: Group 1 - control; Group 2 - Er:YAG laser was applied on the enamel margin before the restoration was placed; Group 3 - a thin layer of calcium hydroxide was applied on the axial wall before the restoration was placed. Each group was divided in 4 sub-groups and the teeth were restored with different aesthetic materials. All samples were submitted to thermocycling and stained with $50 \%$ silver nitrate. Based on the obtained results, we could conclude that there are statistically significant differences between the 12 experimental conditions tested. The samples which presented the greatest microleakage were those treated with Er:YAG laser and restored with light-cured glass ionomer cement, followed by those that received Er:YAG laser and the sandwich technique, the cavities restored with light-cured glass ionomer cement and those restored by means of the sandwich technique, in this order.

UNITERMS: Dental leakage; Dental materials; Lasers.

\section{REFERÊNCIAS BIBLIOGRÁFICAS}

1. ALANI, A. H.; TOH, C. G. Detection of microleakage around dental restorations: a review. Oper Dent, v. 22, n. 4, p. 173-185, 1997.

2. ASMUSSEN, E. The effect of temperature changes on adaptation of resin fillings. Part I. Acta Odont Scand, v. 32, n. 3, p. 161-171, 1974.

3. ASMUSSEN, E. The effect of temperature changes on adaptation of resin fillings. Part II. Acta Odont Scand, v. 32, n. 5, p. 291-297, 1974.

4. BARNES, D. M.; McDONALD, N. J.; THOMPSON, V. P. et al. Microleakage in facial and lingual class $\mathrm{V}$ composite restorations: a comparison. Oper Dent, v. 19, n. 4, p. 133-137, 1994.

5. BOWEN, R. L.; RAPSON, J. E.; DICKSON, G. Hardening shrinkage and hygroscopic expansion of composite resins. J Am Dent Assoc, v. 61, n. 5, p. 654-658, 1982.

6. BRACKETT, W. W.; GUNNIN, T. D.; GILPATRICK, R. O.; BROWNING, W. D. Microleakage of class V compomer and light-cured glass ionomer restorations. J Prosthet Dent, v. 79, n. 3, p. 261-263, 1998.

7. BULLARD, R.; LEINFELDER, K. F.; RUSSEL, C. M. Effect of coefficient of thermal expansion on microleakage. J Am Dent Assoc, v. 116, n. 7, p. 871-874, 1988.

8. BUONOCORE, M. G. A simple method of increasing the adhesion of acrylic filling materials to enamel surfaces. $\mathbf{J}$ Dent Res, v. 34, n. 6, p. 349-353, 1955.

9. CHERSONI, S.; LORENZI, R.; FERRIERI, P.; PRATI, C. Laboratory evaluation of compomers in class $\mathrm{V}$ restorations. Am J Dent, v. 10, n. 3, p. 147-151, 1997.

10. CHOHAYEB, A. A.; RUPP, N. W. Comparison of microleakage of experimental and selected commercially available bonding systems. Dent Mater, v. 5, n. 4, p. 241-243, 1989.

11. COZEAN, C.; ARCORIA, C. J.; PELAGALLI, J.; POWEL, L. Dentistry for the $21^{\text {st }}$ century? Er:YAG laser for teeth. $\mathbf{J}$ Am Dent Assoc, v. 128, p. 1080-1086, 1997.

12. DOUGLAS, W. H.; FIELDS, R. P.; FUNDINGSLAND, J. A comparison between the microleakage of direct and indi- rect composite restorative systems. J Dent, v. 17, n. 4, p. 184-188, 1989.

13. GALE, M. S.; DARVELL, B. W. Thermal cycling procedures for laboratory testing of dental restorations. J Dent, v. 27, n. 2, p. 89-99, 1999.

14. GRIEVE, A. R.; SAUNDERS, W. P.; ALANI, A. H. The effects of dentine bonding agents on marginal leakage of composite restorations - long-term studies. J Oral Rehabil, v. 20, p. 11-18, 1993.

15. GROSS, D.; RAAB, W. H. M.; KELLER, U.; HIBST, R. Surface morphology of dental hard tissues after Er:YAG laser treatment. In: INTERNATIONAL CONGRESS ON LASERS IN DENTISTRY, 1992, Salt Lake City. Proceeding, International Society of Lasers in Dentistry, 1992. p. 133-134.

16. KEHDI, A. B. M. Contribuição ao estudo in vitro da microinfiltração dos preparos de classe $\mathrm{V}$ restaurados com resina composta fotoativada. São Paulo, 1993. 50 p. Dissertação (Mestrado) - Faculdade de Odontologia, Universidade de São Paulo.

17. KUMAZAKI, M. Removal of hard dental tissue (cavity preparation) with the Er:YAG laser. In: INTERNATIONAL CONGRESS ON LASERS IN DENTISTRY, 1994, Singapore. Proceeding, International Society of Lasers in Dentistry, 1994. p. 151-57.

18. LI, Z.; CODE, J. E.; van de MERWE, W. P. Er:YAG laser ablation of enamel and dentin of human teeth: determination of ablation rates at various fluences and pulse repetition rates. Lasers Surg Med, v. 12, p. 625-630, 1992.

19. MARSHALL Jr., G. W.; MARSHALL, S. J.; KINNEY, J. H.; BALOOCH, M. The dentin substrate: structure and properties related to bonding. J Dent, v. 25, n. 6, p. 441-458, 1997.

20. MATOS, A. B. Contribuição ao estudo in vitro da microinfiltração de lesões cervicais não cariosas restauradas com diferentes materiais adesivos e técnicas. São Paulo, 1996, 114 p. Tese (Doutorado) - Faculdade de Odontologia, Universidade de São Paulo.

21. NICHOLSON, J. W.; CROLL, P. Les ciments au verre ionomère: passé, présent et avenir. Clinic, v. 19, n. 1, p. 9-19, 1998.

22. OWENS, B. M.; HALTER, T. K.; BROWN, D. M. Microleakage 
of tooth-colored restorations with a beveled gingival margin. Quintessence Int, v. 29, n. 6, p. 356-361, 1998.

23. RETIEF, D. H. Standardizing laboratory adhesion tests. Am J Dent, v. 4, n. 5, p. 231-236, 1991.

24. SALAMA, F. S.; RIAD, M. I.; ABDEL MEGID, F. Y. Microleakage and marginal gap formation of glass ionomer resin restorations. J Clin Pediatr Dent, v. 20, n. 1, p. 31-36, 1995.

25. SALAMA, F. S. Effect of laser pretreated enamel and dentin of primary teeth on microleakage of different restorative materials. J Clin Pediatr Dent, v. 22, n. 4, p. 285-291, 1998.

26. SANTOS, W. A. G.; BARBOSA, S. V. Reação pulpar aos condicionadores ácidos. Rev ABO Nac, v. 6, n. 3, p. 142-146, 1998.

27. SARACENI, C. H. C. Resistência à tração de um sistema adesivo em superficies dentinárias tratadas com microabrasão por óxido de aluminio e irradiação com laser de Er:YAG. São Paulo, 1998, 114 p. Dissertação
(Mestrado) - Faculdade de Odontologia, Universidade de São Paulo.

28. SHAFFER, S. E.; BARKMEIER, W. W.; KELSEY, W. P. Effects of reduced acid conditioning time on enamel microleakage. Gen Dent, v. 35, n. 4, p. 278-280, 1987.

29. TAYLOR, M. J.; LINCH, E. Microleakage. J Dent, v. 20, n. 2, p. 3-10, 1992.

30. WRIGHT, G. Z.; McCONNEL, R. J.; KELLER, U. Microleakage around resin restorations prepared with an Er:YAG Laser. In: INTERNATIONAL CONGRESS ON LASERS IN DENTISTRY, 1992, Salt Lake City. Proceeding, International Society of Lasers in Dentistry, 1992. p. 99-100.

31. WU, W.; COBB, E. N. A silver staining technique for investigating wear of restorative dental composites. J Biomed Mat Res, v. 15, n. 3, p. 343-348, 1981.

32. WU, W.; COBB, E. N.; DERMANN, K.; RUPP, N. W. Detecting margin leakage of dental composite restorations. J Biomed Mat Res, v. 17, n. 1, p. 37-43, 1983.

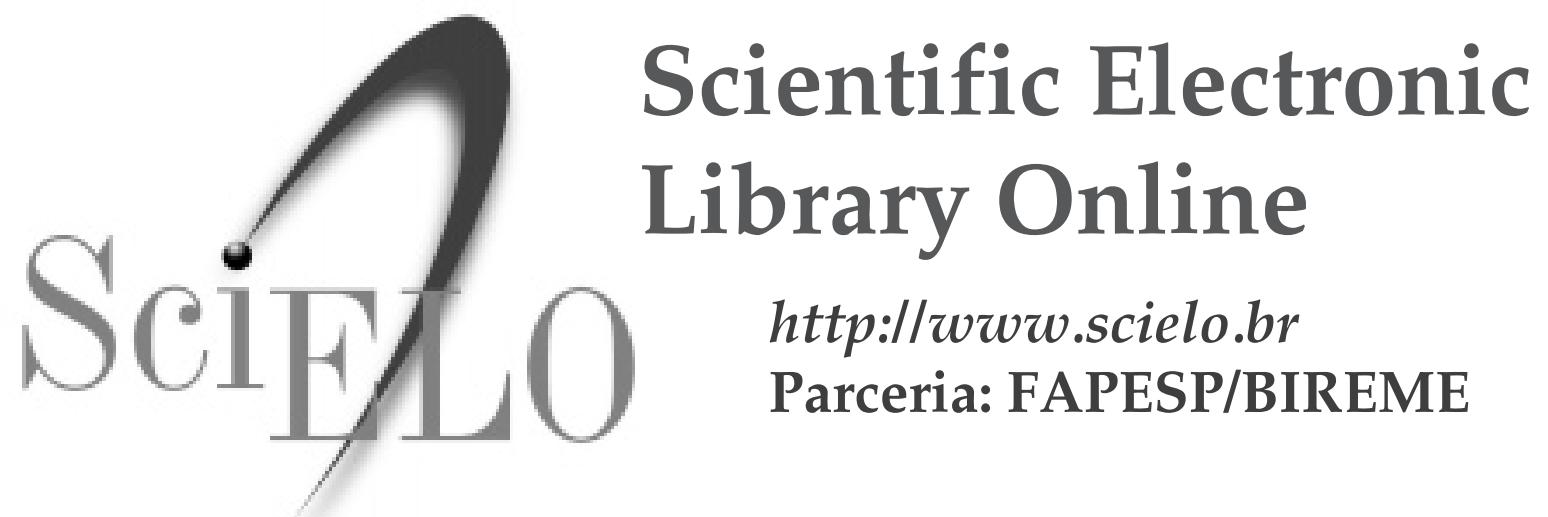

SciELO - Scientific Electronic Library Online é uma coleção eletrônica de revistas científicas disponíveis na Internet. A coleção traz os textos completos de artigos científicos, bases de dados e relatórios de uso e de impacto da literatura científica publicada no site.

Em operação desde 1997, atualmente estão disponíveis 29 revistas brasileiras nas áreas de ciências biológicas e da saúde, ciências sociais e humanas, ciências agrárias, física etc. Novas publicações são incluídas regularmente em várias especialidades.

Entre as revistas de nossa coleção, está a Pesquisa Odontológica Brasileira.

$$
\begin{gathered}
\text { Consulte a Pesquisa Odontológica Brasileira (Revista de Odontologia } \\
\text { da USP) na SciELO - http://www.scielo.br/rousp }
\end{gathered}
$$

